Este é um artigo publicado em acesso aberto sob uma licença Creative Commons https://creativecommons.org/licenses/by-nc/4.0/

\title{
$O$ regime de colaboração nos processos de avaliação institucional nas universidades estaduais da região Centro- Oeste: regulamentações e desafios
}

\author{
Renata Ramos da Silva Carvalho ${ }^{1}$ \\ Lúcia Maria de Assis²
}

Resumo: Este artigo tem por objetivo analisar como o regime de colaboração está expresso nos documentos oficiais dos estados e das universidades estaduais (UEs) da região Centro-Oeste e as contradições quanto a sua materialidade no processo de avaliação institucional. O regime de colaboração está previsto na Constituição Federal de 1988 (CF de 1988), na Lei de Diretrizes e Bases da Educação Nacional - 9.394/96 (LDB) e na Lei do Sistema Nacional de Avaliação da Educação Superior 10.861/04 (Sinaes). Por meio de uma análise teórica e documental, este estudo busca elucidar os desafios desse processo nas universidades estaduais de Goiás (UEG), de Mato Grosso do Sul (Uems) e de Mato Grosso (Unemat). O estudo apresenta uma análise da legislação nacional sobre o regime de colaboração entre os entes federados, em especial, nos processos de avaliação e, também como os documentos dos estados, que regulamentam os seus sistemas estaduais de educação superior e os projetos de avaliação institucional das referidas UEs, preveem (ou não) o regime de colaboração.

Palavras-chave: Universidades estaduais. Regime de colaboração. Avaliação institucional.

\section{The collaboration in the institutional evaluation processes in the state universities of the Central-West Region: regulations and challenges}

Abstract: The study aims to analyze how the system of collaboration process is stated in the official documents of the state and in the State universities of central-west region, and how the process of institutional evaluation is conducted according to the Federal Constitution of 1988 (CF88), to the Education Law 9.394/96 (Lei das Diretrizes e Bases da Educação Nacional - LDBEN), and the law of National System of Evaluation to the Higher Education - 10.861/04 (SINAES). Through a theoretical and documental analysis, it also seeks to clarify the challenges and contradictions of this process in the State Universities of Goiás (UEG), Mato Grosso do Sul (UEMS) and Mato Grosso (UNEMAT). The study presents an analysis of the national legislation on the system of collaboration process between the federal entities, especially in the evaluation processes, as well as how the documents of the States that regulate the state system of higher education and the projects of institutional evaluation of the referred State universities (UEs) predict (or not) the system of collaboration.

Key words: State universities. System of collaboration. Institutional evaluation. 
O regime de colaboração nos processos de avaliação institucional nas universidades estaduais da Região CentroOeste: regulamentações e desafios

\section{Introdução}

As Instituições Estaduais de Ensino Superior (IEES) possuem importante participação no contexto da educação superior no Brasil e compõem uma rede formada por faculdades, centros-universitários e universidades, que atuam em capitais e regiões interioranas de todo o país (ANDRADE, 2012; CARVALHO, 2013). Conforme dados do Censo da Educação Superior do ano de 2015, as IEES foram responsáveis por 31,5\% das matrículas públicas presenciais na educação superior brasileira. Os dados mostram também que elas possuem expressiva atuação no processo de interiorização desse nível educacional nas regiões onde estão localizadas (BRASIL, 2015a).

Desde o surgimento das primeiras IEES observa-se um considerável processo de expansão dessa rede, tanto no aspecto quantitativo com o aumento do número de instituições e de matrículas de graduação, quanto no aspecto qualitativo com a oferta de cursos de pósgraduação stricto sensu. No Brasil, apenas os estados do Sergipe, Rondônia e Acre ainda não possuem Instituições de Educação Superior (IES) mantidas pelo poder público estadual. Segundo os dados do Censo da Educação Superior de 2015, do conjunto das 120 IEES existentes no país, 38 eram universidades, 17 delas estão localizadas em capitais e 21 no interior (BRASIL, 2015a). Cabe ressaltar que três dessas universidades estão localizadas na região Centro-Oeste e constituem objeto deste estudo: a Universidade Estadual de Goiás (UEG), a Universidade Estadual de Mato Grosso do Sul (Uems) e a Universidade do Estado do Mato Grosso (Unemat).

É importante ressaltar que a expansão da educação superior ocorrida nos anos 1990 no Brasil, predominantemente privada, se deu no contexto de uma grande Reforma do Estado pautada pelos princípios neoliberais e sob a mesma lógica que rege o mercado de bens e serviços, levando à formulação, pelos pesquisadores, da expressão "quase-mercado educacional" (SGUISSARDI, 1997). Neste contexto foi instituído também o Exame Nacional de Cursos (ENC-provão), com o objetivo de garantir a qualidade dos cursos ofertados pelas IES e promover a regulação do sistema em grande expansão. Em 2004, o governo federal estabeleceu uma nova política de avaliação da educação superior com o Sistema Nacional de Avaliação da Educação Superior (Sinaes). Desde a sua implantação as políticas de avaliação das IES têm promovido grande impacto na gestão institucional, sobretudo no que diz respeito às consequências que os resultados dos exames de desempenho dos estudantes vêm desencadeando nos processos de supervisão e regulação das IES (BARREYRO; ROTHEN, 2011). 
Nesse contexto os processos de avaliação institucional e de regulação passaram a ser desenvolvidos de maneira integrada, de modo que os processos e os resultados da avaliação formam um complexo banco de dados que pode subsidiar desde a análise do desempenho dos estudantes, das características do corpo docente, dos resultados da auto avaliação institucional em várias dimensões ${ }^{1}$ até o lugar em que a IES se situa no ranking nacional, por meio dos índices que passaram a compor Sinaes ${ }^{2}$, a partir de 2008. Os resultados destes rankings também podem determinar a continuidade ou não da oferta de vagas em um curso, bem como induzir processos de diligências para avaliação, in loco, das condições de funcionamento da IES.

Além dessas consequências, outro processo que decorre desta política é a responsabilização dos docentes e gestores institucionais pelos resultados obtidos pelos cursos (CPC), estimulando ações que vão desde a criação de "cursinhos" preparatórios para os estudantes que farão o Exame Nacional de Desempenho dos Estudantes (Enade) até o desligamento de professores do quadro docente das IES para que possam adequá-lo aos indicadores exigidos pelo Sinaes (ASSIS; AMARAL, 2013). Avaliação institucional e expansão da educação superior pública e privada são, portanto, duas faces do mesmo fenômeno, que visa ampliar e descentralizar a oferta de vagas e centralizar, na União, o processo de avaliação e regulação desta oferta, utilizando-se o princípio da integração e colaboração entre os entes federados.

Tendo em vista a importância das IEES no contexto da oferta de matrículas públicas para a educação superior no Brasil, a necessária implementação do regime de colaboração

\footnotetext{
${ }^{1}$ As dez dimensões do Sinaes são: 1. Missão e PDI; 2. Política para o ensino, a pesquisa, a pós-graduação e a extensão; 3 . Responsabilidade social da IES; 4. Comunicação com a sociedade; 5. As políticas de pessoal, as carreiras do corpo docente e técnico-administrativo; 6. Organização de gestão da IES; 7. Infraestrutura física; 8. Planejamento de avaliação; 9. Políticas de atendimento aos estudantes; 10. Sustentabilidade financeira. Disponível em: <http://portal.inep.gov.br/superior-sinaes-componentes>. Acesso em: 18 out. 2016.

${ }^{2}$ O Indicador de Diferença Entre os Desempenhos Observado e Esperado (IDD) tem o propósito de trazer às instituições informações comparativas dos desempenhos de seus estudantes concluintes em relação aos resultados obtidos, em média, pelas demais instituições cujos perfis de seus estudantes ingressantes são semelhantes. Entende-se que essas informações são boas aproximações do que seria considerado efeito do curso. O Conceito Preliminar de Curso (CPC) é um indicador de qualidade que avalia os cursos superiores.Ele é calculado no ano seguinte ao da realização do Enade de cada área, com base na avaliação de desempenho de estudantes, corpo docente, infraestrutura, recursos didático-pedagógicos e demais insumos, conforme orientação técnica aprovada pela CONAES. O Indice Geral de Cursos (IGC) é um indicador de qualidade que avalia as instituições de educação superior que é calculado anualmente, considerando o CPC dos cursos avaliados no ano do cálculo e nos dois anos anteriores. Sua divulgação refere-se sempre a um triênio, compreendendo assim todas as áreas avaliadas, ou ainda, todo o ciclo avaliativo. Disponível em: <http://portal.inep.gov.br/educacaosuperior/indicadores>. Acesso em: 18.out. 2016.
} 
O regime de colaboração nos processos de avaliação institucional nas universidades estaduais da Região CentroOeste: regulamentações e desafios

entre os entes da federação na expansão e na garantia da qualidade desta oferta e a importância dos processos avaliativos neste contexto, este estudo pretende identificar como está previsto o regime de colaboração nos processos de avaliação institucional nos documentos oficiais dos estados e das UEs da região Centro-Oeste e quais são os principais desafios para sua efetivação.

Neste percurso pretende-se, também, no que diz respeito à avaliação institucional, identificar como o pacto federativo está materializado nas fontes documentais, nessas instituições que são vinculadas aos sistemas de ensino dos estados, ou seja, nos documentos oficiais da UEG, Unemat e Uems. Conforme previsão legal, "ao estado cabe organizar, manter e desenvolver os órgãos e instituições oficiais dos seus sistemas de ensino" (BRASIL, 1996, art. 10). Compete ainda aos estados da federação, “autorizar, reconhecer, credenciar, supervisionar e avaliar, respectivamente, os cursos das instituições de educação superior e os estabelecimentos do seu sistema de ensino" (BRASIL, 1996, art. 10).

\section{0 regime de colaboração e o processo de avaliação institucional no sistema federal de educação superior}

O Sistema Federal de Educação Superior, conforme o artigo $2^{\circ}$ do Decreto 5.773/2006 $(\text { BRASIL, 2006) })^{3}$ é formado pelas instituições federais e as IES criadas e mantidas pela iniciativa privada e também pelos órgãos federais de educação superior. O referido Decreto estabelece que a avaliação, no âmbito desse sistema, seja realizada com base nas diretrizes da Lei 10.861/2004, que instituiu o Sinaes, com o objetivo de melhorar a qualidade da educação superior e de orientar a sua expansão "por meio da valorização de sua missão pública, da promoção dos valores democráticos, do respeito à diferença e à diversidade, da afirmação da autonomia e da identidade institucional" (BRASIL, 2004, art. 1). Esse sistema tem por objetivo colaborar com a melhoria da eficácia institucional e da efetividade acadêmica e social das IES, porém observam-se várias contradições quanto à efetivação e materialidade do Sinaes. Segundo Barreyro e Rothen (2011) "na implementação da política de avaliação institucional explicitada na lei do Sinaes, o embate entre as duas concepções de avaliação continua presente. Diversos documentos divulgados no âmbito do MEC adotaram posturas diferentes, ora enfatizando o processo interno de autoavaliação, ora enfatizando a

\footnotetext{
${ }^{3}$ Dispõe sobre o exercício das funções de regulação, supervisão e avaliação de instituições de educação superior e cursos superiores de graduação e sequenciais no sistema federal de ensino.
} 
predominância da padronização de indicadores quantitativos. Efetivamente, o ciclo proposto pelo Sinaes ainda não se concluiu da forma prevista" (p. 83). Está previsto também que o Sinaes seja desenvolvido em cooperação com os sistemas de ensino dos estados e do Distrito Federal.

Tais dispositivos legais contribuem para que as UEs se diferenciem das demais IES do país, inclusive quanto aos seus processos de avaliação e demais processos regulatórios, considerando que elas não integram o Sistema Federal de Educação Superior. Segundo Fialho (2012), essa diferenciação coloca as universidades estaduais em um profundo hiato na estruturação da organização superior no Brasil, cabendo o questionamento de qual seria o lugar ocupado por elas nessa estruturação.

A autora evidencia essa contradição ao afirmar que as UEs são "universidades sim, portanto, instituições de educação superior, entretanto, não vinculadas à União; instituições de educação superior sim, mas universidades estaduais, portanto, não integrantes do sistema federal de educação superior" (FIALHO, 2012, p. 82). A legislação que trata desse assunto colabora para ratificar a contradição existente nessa indefinição do lugar das UEs na organização da educação superior no país, pois tanto a CF de 1988 quanto a LDB preconizam que a educação no Brasil seja exercida sob o pilar do regime de colaboração entre os entes federados, inclusive em seus processos de avaliação institucional.

A esse respeito, a CF de 1988 prevê como competência privativa da União legislar sobre as diretrizes e bases da educação nacional (art. 22, inciso XXIV). Concorrentemente, competem à União, aos estados e ao Distrito Federal legislarem sobre a educação (art. 24, inciso IX). Assim, ancorados nas diretrizes gerais estabelecidas pela União, os estados e o Distrito Federal regulam suas normas educacionais. O artigo supracitado não menciona os municípios que vão aparecer no art. 211 da CF de 1988, juntamente com os demais entes federados, com a incumbência de organizar, em regime de colaboração, os seus sistemas de ensino.

Nessa perspectiva de atuação, cabe à União organizar o Sistema Federal de ensino e o dos territórios. Ela também é a responsável pelo financiamento das instituições de ensino públicas federais e exerce "a função redistributiva e supletiva, de forma a garantir equalização de oportunidades educacionais e padrão mínimo de qualidade do ensino mediante assistência técnica e financeira aos Estados, ao Distrito Federal e aos Municípios" (BRASIL, CF, art. $\left.211, \S 1^{\circ}\right)$.

Já os estados e Distrito Federal "possuem atuação prioritária no ensino fundamental e médio e os Municípios no ensino fundamental e educação infantil” (CF88, art. 211, § $2^{\circ}$ e $\left.3^{\circ}\right)$. 
O regime de colaboração nos processos de avaliação institucional nas universidades estaduais da Região CentroOeste: regulamentações e desafios

Como se vê, há uma lacuna na CF de 1988 sobre a responsabilidade dos entes federados pela oferta de educação superior pública e não existe nenhuma menção de competência exclusiva da União nesse nível educacional. O texto constitucional também não faz alusão às UEs e, mesmo nos parágrafos seguintes, não há referência à educação superior. Embora a CF de 1988 apresente como competência dos estados brasileiros e do Distrito Federal o atendimento à educação básica, é significativa a atuação dos estados na oferta da educação superior pública. Isso acontece por meio de seus sistemas estaduais de educação superior. Para tratar dessa questão, a LDB retoma o artigo 211 da CF de 1988 sob o Título IV - Da Organização da Educação Nacional, como destacado a seguir:

\footnotetext{
Art. $8^{\circ}$ - A União, os Estados, o Distrito Federal e os Municípios organizarão, em regime de colaboração, os respectivos sistemas de ensino.

$\S 1^{\circ}$ Caberá à União a coordenação da política nacional de educação, articulando os diferentes níveis e sistemas e exercendo função normativa, redistributiva e supletiva em relação às demais instâncias educacionais.

Art. $9^{\circ}$ A União incumbir-se-á de:

II - organizar, manter e desenvolver os órgãos e instituições oficiais do sistema federal de ensino e o dos Territórios;

III - prestar assistência técnica e financeira aos Estados, ao Distrito Federal e aos Municípios para o desenvolvimento de seus sistemas de ensino e o atendimento prioritário à escolaridade obrigatória, exercendo sua função redistributiva e supletiva;

VI - assegurar processo nacional de avaliação do rendimento escolar no ensino fundamental, médio e superior, em colaboração com os sistemas de ensino, objetivando a definição de prioridades e a melhoria da qualidade do ensino;

VIII - assegurar processo nacional de avaliação das instituições de educação superior, com a cooperação dos sistemas que tiverem responsabilidade sobre este nível de ensino;

IX - autorizar, reconhecer, credenciar, supervisionar e avaliar, respectivamente, os cursos das instituições de educação superior e os estabelecimentos do seu sistema de ensino.

$\S 3^{\circ}$ As atribuições constantes do inciso IX poderão ser delegadas aos Estados e ao Distrito Federal, desde que mantenham instituições de educação superior.

Art. 10. Os Estados incumbir-se-ão de:

I - organizar, manter e desenvolver os órgãos e instituições oficiais dos seus sistemas de ensino;

IV - autorizar, reconhecer, credenciar, supervisionar e avaliar, respectivamente, os cursos das instituições de educação superior e os estabelecimentos do seu sistema de ensino;

V - baixar normas complementares para o seu sistema de ensino (BRASIL, 1996, art. 8).
}

Pode-se perceber que, dentre as inúmeras incumbências da União, cabe também a responsabilidade de coordenar e articular a política nacional de educação em seus diversos níveis e sistemas. Ainda no rol de suas competências, a União deve assegurar o processo nacional de avaliação das IES em cooperação com os demais entes federados que possuam seus sistemas próprios de educação superior. Nesse quesito, a União poderá delegar aos estados e ao Distrito Federal a atribuição de autorizar, reconhecer, credenciar, supervisionar e avaliar desde que mantenham IES próprias.

Sobre a regulamentação dos processos de avaliação da educação superior, o artigo 46 da LDB trata dessa questão e prevê a obrigatoriedade e periodicidade desses processos. Assim 
define a referida Lei: "a autorização e o reconhecimento de cursos, bem como o credenciamento de instituições de educação superior, terão prazos limitados, sendo renovados, periodicamente, após processo regular de avaliação" (BRASIL, 1996, art. 46).

Os sistemas estaduais de educação superior, conforme expressa o art. 17 da LDB, compreendem as instituições de ensino por eles mantidas e as IES mantidas pelo poder público municipal. Essa prerrogativa dá autonomia aos estados brasileiros para ofertarem a educação superior pública, cabendo a eles a responsabilidade nos processos que envolvem autorização, reconhecimento, credenciamento, supervisão e avaliação das IES que lhes são subordinadas, como mencionado anteriormente.

Nessa perspectiva, a CF de 1988 e a LDB apresentam os subsídios legais que fundamentam o regime de colaboração entre os entes federados e trazem também algumas definições. No entanto, percebe-se que há uma indefinição em relação ao lugar das IEES no contexto da educação superior brasileira, que pode ser percebida nas lacunas existentes na legislação e quanto à responsabilidade de cada ente na oferta de educação superior pública.

Uma destas lacunas pode ser evidenciada na regulamentação dos processos de avaliação dessas instituições. A própria legislação ora coloca a avaliação como competência dos estados, ora institui a União como responsável por sua definição e ora determina que a avaliação seja realizada em regime de cooperação. Essas contradições quanto a essa definição pode interferir na organização e gestão administrativa e acadêmica das IEES, considerando que as orientações da União e dos demais entes federados nem sempre são convergentes. Acreditamos que o enfrentamento das intricadas questões vivenciadas pelas UEs, em especial no que tange aos seus processos de avaliação institucional, passa pela discussão do lugar e do papel dessas instituições de ensino superior no debate do Sistema Nacional de Educação e no do regime de colaboração entre União, estados e municípios. A base legal para a consolidação desse regime de colaboração vem expressa na CF de 1988 e na LDB, então,

É hora de construir essa nova realidade e prosseguir a caminhada. Não há como enfrentar a problemática vivenciada pelas universidades estaduais de todo o país sem colocar na mesa o sistema nacional de educação e o regime de colaboração entre União, Estados e Municípios (FIALHO, 2012, p. 18).

Segundo Trindade (2007), na tentativa de estreitar as relações entre os sistemas estaduais de educação superior para a implantação do Sinaes, foi assinado em 2004, um Protocolo de intenções entre a Comissão Nacional de Avaliação da Educação Superior (Conaes) e o Fórum Nacional de Conselhos Estaduais de Educação (FNCE). Por esse documento, o FNCE se propôs a estimular a adesão dos Conselhos Estaduais de Educação 
O regime de colaboração nos processos de avaliação institucional nas universidades estaduais da Região CentroOeste: regulamentações e desafios

(CEEs) ao processo nacional de avaliação da educação superior e a Conaes se dispôs a prestar colaboração técnica para os estados e Distrito Federal desenvolverem seus sistemas próprios de avaliação assegurando a articulação com o Sinaes. Oliveira (2015, p. 156) acrescenta que "alguns Conselhos viram com bons olhos a proposta, outros, nem tanto, e acabaram por retardar essa aproximação".

O estado de Santa Catarina foi o primeiro a celebrar acordo, por meio de assinatura de Termo de Cooperação Técnica com a Conaes para adesão ao Sinaes em março de 2005. Trindade (2007) ressalta que entre 2005 e 2006 outros nove CEEs também assinaram Termo de Cooperação Técnica, sendo eles os do estado de Mato Grosso (21/09/2005), Ceará (29/09/2005), Pernambuco (25/11/2005), Minas Gerais (25/11/2005), Rio Grande do Sul (25/11/2005), Bahia (25/11/2005), Maranhão (25/11/2005), Rio de Janeiro (14/12/2005) e o Pará (23/3/2006).

Embora o FNCE e a Conaes tenham essa parceria visando estabelecer o regime de colaboração nos processos de avaliação institucional entre os sistemas de educação superior federal e estadual, essa articulação é permeada por conflitos e desafios para a sua concretude. Oliveira (2015) ao realizar estudo sobre o processo de avaliação da educação superior e o regime de colaboração no contexto das IEES identificou, por meio da análise realizada nas atas das reuniões da Conaes no período de 2006 a 2014, vários desafios ainda presentes para essa efetivação. Além dos entraves postos pela legislação e pelas questões logísticas, operacionais e tecnológicas, o autor destaca a existência de tensionamentos entre Conaes e CEEs sobre as normatizações para a definição das comissões verificadoras. A Conaes preza pela "uniformidade" do processo e metodologia já prevista pelo Sinaes e muitos CEEs não abrem mão de participarem do processo e de definirem as comissões verificadoras locais com a alegação da necessidade de resguardarem as particularidades de seus sistemas. Por meio de análise realizada em atas de reuniões da Conaes de 2011, Oliveira (2015) ressalta que,

\footnotetext{
este fragmento da ata da CONAES traduz-se num indício de como são as dificuldades encontradas pela Comissão (CONAES) em estabelecer acordos de cooperação com os sistemas estaduais. Mesmo que estes últimos tenham imensa vontade em participar dos trâmites do SINAES, eles não abrem mão de indicar pessoas das próprias comissões de avaliação instituídas pelos próprios sistemas estaduais, coisa que o SINAES não permite. A Bahia não é um caso isolado. Outros conselhos estaduais que buscam acordos com a CONAES/INEP também encontram esta dificuldade. Portanto, para além dos entraves da legislação e do próprio Sistema e-MEC, há também as comissões de avaliação instituídas pelos próprios sistemas estaduais que acabam por interferir na construção de um regime de colaboração entre os sistemas educacionais...

Importante observar, no contexto das atas de 2011, que as IES estaduais optam por fazer apenas o Enade, e isso é apenas uma parte do SINAES. Ou seja, elas acabam não participando do SINAES em sua totalidade (CONAES, ATA 76, 09 e 10/05/2011). Até aquele momento
} 
(2011), a CONAES procurava soluções a partir do e-MEC para acomodar os sistemas estaduais. (p. 162 e 163).

Fica evidente que há uma disputa por espaços entre a Conaes e os CEEs, a primeira buscando garantir os pilares metodológicos do Sinaes e o segundo reiterando a necessidade de participação nos processos por meio das comissões próprias a fim de resguardar as especificidades dos sistemas estaduais.

Importante ressaltar que a luta da CONAES por um sistema nacional de avaliação está pautada num modelo onde a vantagem da comparabilidade dos resultados é o fio condutor do sistema, o que é muito difícil utilizando sistemas estaduais diferenciados (CONAES, ATA 86, 17/04/2012). Esta, portanto, é uma pauta controversa na queda de braços entre CONAES e CEEs, pois os Estados entendem que com a autonomia de seus sistemas e as especificidades de cada um, caberia a eles (Estados) indicarem as comissões, o que não é do agrado da CONAES. (OLIVEIRA, 2015, p. 167).

É possível identificar nessa tentativa de integração entre estados e a União para a efetividade do Sinaes, conflitos provenientes por essa disputa de interesses que interferem de modo significativo na concretude do regime de colaboração. Tendo em vista este cenário, apresentamos, na segunda parte desse estudo, como está expresso (ou não) em documentos oficiais e institucionais, os desafios vivenciados pelas universidades estaduais da região Centro-Oeste para estabelecer esta cooperação em seus processos de avaliação institucional.

\section{0 regime de colaboração e o processo de avaliação institucional nas universidades estaduais da região Centro-Oeste expresso nos documentos oficiais}

O regime de colaboração consta na legislação que regulamenta a educação e também nas que versam sobre os processos de avaliação institucional das IES do país. Na tentativa de elucidar a forma como está prevista essa colaboração entre o Ministério da Educação (MEC), o Instituto Nacional de Estudos e Pesquisas Anísio Teixeira (Inep), a Conaes e os sistemas estaduais, por meio de seus órgãos representativos e de suas UEs, realizou-se uma análise dos documentos normativos que regulamentam o Sistema Estadual de Educação Superior nos estados de Goiás, Mato Grosso e Mato Grosso do Sul e, dos Projetos de Avaliação Institucional $^{4}$ da UEG e Unemat e Uems, buscando apreender como se configura o regime de colaboração nos processos de avaliação institucional explícito nesses documentos.

\footnotetext{
${ }^{4}$ Foi utilizado nesta análise o Projeto de Avaliação (ou Autoavaliação) Institucional mais recente disponível em meio eletrônico na página de cada instituição.
} 
O regime de colaboração nos processos de avaliação institucional nas universidades estaduais da Região CentroOeste: regulamentações e desafios

\section{O Sistema Estadual de Mato Grosso}

As normas para a organização e funcionamento das IES pertencentes ao Sistema Estadual de Educação Superior no estado do Mato Grosso estão previstas na Resolução Normativa n. ${ }^{\circ}$ 311/2008, do Conselho Estadual de Educação do Mato Grosso (CEE/MT). Essa Resolução institui a Secretaria de Estado de Ciência e Tecnologia (Secitec/MT) como a responsável pela supervisão do Sistema, deixando a função de regulação na incumbência do CEE/MT. Nesse documento há lacunas quanto à definição de competência e de acompanhamento dos processos de avaliação institucional das IES a ele vinculadas. Consta, porém, que essa Resolução foi elaborada e subsidiada pelo Termo de Cooperação firmado entre o CEE/MT e o Ministério da Educação/Sinaes.

Esse Termo de Cooperação Técnica foi celebrado no ano de 2005 com o objetivo de estabelecer o regime de colaboração previsto na legislação a fim de ampliar a atuação do CEE/MT nos processos de avaliação externa preconizada pelo Sinaes. Pelo presente instrumento cabe ao CEE/MT, dentre outras atribuições: apoiar e orientar a participação das IES do Sistema Estadual na avaliação do desempenho dos estudantes - Enade; avaliar dinâmicas, procedimentos e mecanismos da avaliação institucional e dos cursos, propondo, se necessário, procedimentos e mecanismos complementares; garantir a integração dos instrumentos de avaliação para a consolidação do Sinaes e apoiar as Comissões Próprias de Avaliação (CPAs) na condução dos processos internos de avaliação da IES. Ao MEC/Sinaes caberá:

I - Promover a articulação com o CEE/MT, estabelecendo ações e indicadores comuns de avaliação e supervisão da Educação Superior;

II - Subsidiar o CEE/MT para a formulação de políticas de educação superior em médio e longo prazos;

III - Realizar periodicamente, em conjunto com o CEE/MT, a avaliação do regime de colaboração estabelecido nos termos ora propostos e as ações de melhoramento dele decorrentes;

IV - Estimular e realizar periodicamente, programas de capacitação dos avaliadores para as práticas de avaliação de educação superior do Estado de Mato Grosso;

V - Encaminhar ao Conselho Estadual de Educação, os relatórios dos resultados do ENADE do perfil sócio - econômico dos participantes da avaliação dos coordenadores do curso;

VI - Assegurar o reconhecimento dos resultados da avaliação da Educação Superior realizada pelo CEE/MT no contexto Sistema Nacional (MATO GROSSO, 2005, p. 3).

Pelas atribuições estabelecidas no Termo de Cooperação Técnica entre CEE/MT e MEC/Conaes há, por parte desses órgãos, a intenção de promover a articulação dos processos avaliativos das IES vinculadas ao Sistema Estadual de Educação Superior de Mato Grosso ao Sinaes, porém o CEE/MT poderá avaliar e propor instrumentos complementares ao processo de avaliação. 
A avaliação dessas IES é mencionada na Resolução 311/2008 do CEE/MT, que trata das questões de recredenciamento e de supervisão. A análise desse dispositivo legal revela que a avaliação institucional está vinculada aos procedimentos regulatórios, sendo seus resultados utilizados como subsídios para a tomada de decisão nos processos de recredenciamento pelo CEE/MT e na supervisão das IES do Sistema Estadual realizada pela Secitec/MT. Conforme o Projeto de Avaliação Institucional da Unemat - triênio 2015 a 2018 - as competências relacionadas à regulação e à avaliação da educação superior em Mato Grosso estão assim definidas:

Compete à UNEMAT a autoavaliação (CPA); à Secretaria de Ciência e Tecnologia - SECITEC a avaliação externa (Banco de avaliadores) e ao Conselho Estadual de Educação - CEE-MT a regulação e emissão dos atos autorizativos a partir dos resultados da Autoavaliação (CPA), avaliação externa/SECITEC (ACG), ENADE, e os indicadores de qualidade (IDD, CPC, IGC) (MATO GROSSO, 2008, p. 8).

Além das atribuições destacadas acima, esse projeto se ancora nas regulamentações do Sinaes para instituir as diretrizes para o processo de avaliação e prevê mudanças estruturais nos futuros relatórios a serem produzidos para atenderem ao Sinaes, por meio de uma nova diretriz da Diretoria de Avaliação da Educação Superior do Inep (Daes/Inep), a Nota Técnica Inep/Daes/Conaes n. 65 (BRASIL, 2015b). Na análise realizada nesse documento não se constatou questões referentes ao regime de cooperação entre os órgãos/entidades/entes federados no processo de avaliação institucional.

Pela apreciação realizada no Projeto de Avaliação Institucional da Unemat não há menção quanto a forma como ocorre a integração dos órgãos envolvidos e a Unemat na condução do Sinaes, que é a política de avaliação institucional adotada pela IES. Sobre esse aspecto, ao analisarem a operacionalização do regime de colaboração no processo de avaliação da Unemat, Lima, Cunha e Silva (2014) tecem a seguinte consideração:

cada órgão e ente federado está preocupado em exercer bem a sua função, porém não observamos uma preocupação com a integração dos diversos instrumentos de avaliação do SINAES (avaliação institucional, avaliação dos cursos e ENADE), esse princípio para a integração dos diversos instrumentos para avaliar a qualidade institucional fica comprometida, já que o primeiro (avaliação institucional) é de responsabilidade da IES com prestação de contas à CONAES/INEP, SECITEC/MT e CEE/MT; o segundo (avaliação e supervisão dos avaliadores externos) fica sob a responsabilidade da SECITEC/MT e o terceiro ENADE totalmente operacionalizado pela CONAES/INEP e os atos autorizativos ficam sob a responsabilidade do CEE/MT. Ao que nos parece, nessa complexa rede de atribuições se perde a função central do SINAES, que é a avaliação e melhoria da qualidade da IES a partir da integração de diversos instrumentos avaliativos (LIMA; CUNHA; SILVA, 2014, p. 113).

De acordo com o Projeto de Avaliação Institucional da Unemat - 2015-2018, o Termo de Cooperação Técnica, firmado entre o CEE/MT e a Conaes estabelece a adesão da Unemat 
O regime de colaboração nos processos de avaliação institucional nas universidades estaduais da Região CentroOeste: regulamentações e desafios

ao Sinaes, bem como das demais IES pertencentes ao Sistema Estadual de Educação Superior de Mato Grosso. Esse acordo tem por finalidade articular o processo de avaliação do Sistema Estadual ao nacional, visando ao alcance dos objetivos do Sinaes. No entanto,

Observa-se no Termo de cooperação técnica a falta de clareza sobre essa homologação da avaliação pela CONAES. A Resolução 311/2008 estabelece as funções do CEE/MT e da SECITEC/MT, porém não deixa explícito com se darão as relações destas instâncias como o SINAES. De posse dessas inconcretudes no processo de colaboração entre os entes federados em relação à avaliação e à regulação do Sistema estadual de Mato Grosso, a UNEMAT continua operacionalizando o seu processo de avaliação institucional, mas fica na balança, ora prestando informações ao INEP (Censo da Educação Superior, ENADE, CPA e outras tantas), ora apresentando informações à SECITEC/MT (comissão externa de avaliadores), ora atendendo as recomendações dos atos autorizativos do CEE/MT (LIMA; CUNHA; SILVA 2014, p. 114).

\section{O Sistema Estadual de Mato Grosso do Sul}

No estado do Mato Grosso do Sul as normas para a regulação, supervisão e avaliação das IES, pertencentes ao Sistema Estadual de Educação Superior, estão previstas na Deliberação n. ${ }^{\circ}$ 9.042, de 27 de fevereiro de 2009, do Conselho Estadual de Educação de Mato Grosso do Sul (CEE/MS). Esse documento estabelece que a Secretaria de Estado de Educação de Mato Grosso do Sul (SED/MS) é a responsável pela supervisão de suas IES e atribui ao CEE/MS a incumbência pela regulação do sistema. Conforme o art. $4^{\circ}$ da referida Deliberação, a avaliação fica por conta das IES e da SED/MS. A fim de garantir a melhoria da qualidade da educação superior e de se tornar referência para os processos de regulação e supervisão, a avaliação será realizada segundo as regulamentações do CEE/MS. Ainda sobre essa questão, são ressaltados também os seguintes pontos:

Art. 51. A avaliação da educação superior compreende as seguintes dimensões:

I - avaliações institucionais interna e externas;

II - avaliação dos cursos;

III - avaliação do desempenho acadêmico dos estudantes.

Art. 52. A avaliação interna da instituição, de responsabilidade da comunidade institucional, será coordenada pela Comissão Própria de Avaliação - CPA, em conformidade com as normas vigentes.

Art. 53. A avaliação da educação superior, à exceção da avaliação interna, é responsabilidade da SED/MS, com base nas normas deste Conselho.

Parágrafo único. A SED/MS poderá realizar a avaliação, em regime de colaboração com outros órgãos dos sistemas de ensino (MATO GROSSO DOS SUL, 2009, p. 10).

As diretrizes e orientações para o processo de avaliação na normatização do CEE/MS são de caráter geral. Elas conferem à IES a responsabilidade pela avaliação interna. Essas diretrizes outorgam também à SED/MS a atribuição para realizar a avaliação em regime de colaboração com outros órgãos. Entretanto, o documento não detalha ou específica quais e como seria essa colaboração. Para Souza (2012), o processo de avaliação institucional da 
Uems é permeado por indefinições e não há uma especificidade de cooperação entre os entes federados. Os artigos 54, 55 e 56 do referido documento enfatizam o papel do Estado regulador e preveem a organização da avaliação da seguinte forma:

Art. 54. A avaliação prevista nesta Deliberação será organizada em ciclos avaliativos com duração máxima de:

I - dez anos, como referencial básico para recredenciamento de universidades;

II - cinco anos, como referencial básico para recredenciamento de centros universitários e faculdades e, ainda, para reconhecimento e renovação de reconhecimento de cursos.

Art. 55. A avaliação, como referencial básico para regulação de instituições e de cursos, incluirá avaliação in loco e resultará na atribuição de conceitos, conforme uma escala de cinco níveis, em consonância com os parâmetros nacionais.

Art. 56. A obtenção de conceitos insatisfatórios nas avaliações periódicas, utilizadas como base nos processos de recredenciamento de instituições, de reconhecimento e de renovação de reconhecimento de cursos de graduação, enseja a celebração de protocolo de compromisso da instituição com a SED/MS (MATO GROSSO DO SUL, 2009, p. 11).

Ao estabelecer as normas de regulação, supervisão e avaliação de IES e também dos demais cursos tanto de graduação quanto aqueles oferecidos na modalidade "sequencial" no Sistema Estadual, o CEE/MS firma adesão ao Sinaes e aos outros instrumentos do Sistema Federal, mesmo que parcialmente. Porém, segundo Souza (2012), o processo de avaliação institucional da Uems esbarra em alguns desafios, dentre eles, a falta de cooperação entre os entes federados que compromete o desenvolvimento do processo avaliativo. Diante disso,

a repercussão da relação entre a União e o sistema estadual de ensino nas políticas avaliativas da UEMS é observada por meio da adesão automática da Instituição às normas do sistema federal. Na ausência de normatização pelo sistema estadual no qual está inserida, a Universidade instituiu a participação dos seus alunos no Exame Nacional de Desempenho dos Estudantes (ENADE) e passou a realizar a sua autoavaliação de acordo com o SINAES. Assim, é possível inferir que o poder regulatório exercido pela União induz as ações institucionais, mesmo em contextos próprios e autônomos como é o caso da UEMS. Na avaliação da educação superior o regime de colaboração entre os entes federados tem se concretizado como um processo de cumprimento de normas, o que não permite a configuração do SINAES como um sistema de cooperação (SOUZA, 2012, p. 6).

A falta de clareza na apresentação do regime de colaboração entre os entes federados, conforme expõe Souza (2012), pode ser ratificada no texto do Projeto de Autoavaliação Institucional da Uems. O documento não faz menção ao regime de colaboração e nem apresenta seus possíveis desafios no processo de avaliação institucional da instituição, porém, afirma que o processo de autoavaliação seguiu as normas e procedimentos do Sinaes.

\section{O Sistema Estadual em Goiás}

No estado de Goiás, as regulamentações para o Sistema Estadual de Educação Superior foram reformuladas por meio da aprovação da Resolução CEE/PLENO, n. 03, de 29 
O regime de colaboração nos processos de avaliação institucional nas universidades estaduais da Região CentroOeste: regulamentações e desafios

de abril de 2016. Essa norma estabelece as regras para esse sistema e revoga a Resolução CEE/PLENO, n.02, de 06 de julho de 2006. O instrumento de avaliação de cursos presenciais de graduação também foi aprovado juntamente com a Resolução CEE-GO/PLENO n. 03/2016. A elaboração desse dispositivo legal teve como finalidade os seguintes princípios:

1 - Estabelecer critérios que venham ao encontro das atuais necessidades de avaliação e regulação das instituições e cursos jurisdicionados ao Sistema Estadual de Educação Superior do estado de Goiás;

2 - Atualizar os instrumentos utilizados pelos avaliadores, evitando a dubiedade de interpretação;

3 - Estabelecer parâmetros para a orientação dos avaliadores, considerando as condições de oferta de ensino, de pesquisa e de extensão;

4 - Elaborar novos instrumentos de avaliação;

5 - Adotar uma metodologia de avaliação própria do Sistema Estadual de Educação Superior;

6 - Estabelecer roteiros para a elaboração dos documentos institucionais como: PDI, PPC, regimento, relatório da Comissão Própria de Avaliação (CPA);

7 - Incluir o relatório da CPA como fonte de coleta de informações por ocasião da avaliação in loco;

8 - Compatibilizar os instrumentos avaliativos com os utilizados no Sistema Federal, respeitadas as especificidades regionais que marcam o Sistema Estadual de Educação Superior; 9 - Incluir os resultados das avaliações externas (Exame Nacional de cursos - ENADE, Índice Geral de Cursos - IGC) como balizadores dos indicadores de avaliação interna da instituição de educação superior e do Conselho Estadual de Educação;

10 - Identificar a contribuição da instituição de educação superior e dos seus cursos para o crescimento e para o desenvolvimento local, da micro e da mesorregião (GOIÁS, 2016, p. 1).

Observa-se que dos dez princípios mencionados na Resolução 3/2016, nove vinculamse direta e indiretamente às questões ligadas à avaliação e seus processos. Diferentemente dos estados de Mato Grosso e Mato Grosso do Sul, em Goiás os processos de avaliação, regulação e supervisão estão concentrados no $\mathrm{CEE} / \mathrm{GO}$, logo, não há a participação de outro órgão ou secretaria estadual. Destaca-se na análise do texto da Resolução CEE-GO/PLENO n. 03/2016 a intenção de ressaltar os instrumentos e procedimentos do CEE/GO. Há também no item 8 a intenção do CEE/GO em compatibilizar os novos instrumentos com os utilizados no Sistema Federal. Assim, os processos de avaliação do CEE/GO são subsidiados pela União por meio do Sinaes, que consiste em um "referencial balizador" para a emissão do conceito final (GOIÁS, 2016, art. 10).

Questões mais específicas e detalhadas sobre o regime de colaboração nos processos de avaliação institucional das IES de Goiás não foram identificadas durante a análise do referido documento. A Resolução 03/2016 só o menciona de modo indireto e sem tratar de sua operacionalização. No item reservado à avaliação institucional consta que a

Art. 16. Avaliação Institucional caracteriza-se por uma construção processual e coletiva que envolve a gestão acadêmica e administrativa e visa diagnosticar, analisar e aperfeiçoar as Instituições de Educação Superior (IES) em suas múltiplas dimensões. 
$\S 1^{\circ}$ A avaliação institucional é um processo sistêmico, participativo e global: sistêmico por ser interativo, contínuo e permanente; participativo por ser executado pela comunidade interna e externa; global por abranger as condições de oferta de todos os programas, cursos e atividades da instituição.

$\S 2^{\circ} \mathrm{A}$ avaliação institucional, deve ser planejada com base no Projeto de avaliação institucional e efetivada:

a. pela comunidade institucional, direção, professores, alunos, funcionários administrativos, representação externa, sob a supervisão da Comissão Própria de Avaliação (CPA);

b. pelo Conselho Estadual de Educação, que decide sobre o seu credenciamento e recredenciamento, a autorização, o reconhecimento, e a renovação de conhecimento de seus cursos, para isso utilizando-se, inclusive, de comissões ad hoc;

c. pelo Ministério da Educação, por meio do Censo da Educação Superior e ENADE, podendo ser desdobrada em convênios entre Conselhos de Educação e MEC, de acordo com legislação que rege o regime de cooperação entre sistemas educacionais.

$\S 3^{\circ}$ A Comissão Própria de Avaliação (CPA), responsável pela Avaliação Institucional, é órgão composto por membros da comunidade interna e externa da IES, nomeados pelo dirigente máximo da instituição, mas independente dos Conselhos Superiores da Instituição.

$\S 4^{\circ} \mathrm{O}$ relatório anual produzido pela CPA deverá ser encaminhado ao CEE para análise e, se necessário, providências, não desobrigando a Instituição de outros encaminhamentos, em especial junto ao SINAES (GOIÁS, 2016, art.16).

Conforme dispõe o $\S 2^{\circ}$ do artigo 16 da Resolução 03/2016, a avaliação institucional deve ser planejada e efetivada pela comunidade, pelo CEE/GO e pelo MEC, via Censo da Educação Superior e Enade. Entretanto, não está previsto como se dará essa cooperação entre esses três órgãos e seus respectivos instrumentos de avaliação. No item "c" da citação acima, o regime de cooperação é tratado como uma expectativa que poderá ser implantada por meio de convênios entre CEE/GO e MEC. Outro ponto a ser destacado se refere à forma de nomeação da CPA. De acordo com o contido na citação, essa comissão de avaliação será nomeada pelo dirigente da IES e não por escolha entre os pares. Segundo determina o ${4^{\circ}}^{\circ}$ o relatório de autoavaliação, amparado nos princípios do Sinaes, deve ser encaminhado ao CEE/GO para fins de análise e como subsídio para os demais processos regulatórios e de supervisão. Com isso, as IES subordinadas ao Sistema Estadual de Educação Superior de Goiás sofrem duplo controle, conforme pode-se constatar no documento transcrito a seguir:

\footnotetext{
Art. 17 - Parágrafo único - Toda avaliação tem, necessariamente, de considerar a autoavaliação institucional (ou avaliação interna), realizada pela instituição, com a participação de todos os segmentos (administração superior, professores, funcionários administrativos e alunos) e a avaliação externa, realizada pelo CEE e pelo MEC/INEP no que tange aos índices obtidos nas avaliações nacionais, ENADE e dados do Censo da educação superior.

Art. 18. O CEE, ao término do processo, emitirá conceito de avaliação por escala de cinco níveis, de 01 (um) a 5 (cinco) de acordo com os indicadores estabelecidos no instrumento de avaliação deste Conselho (GOIÁS, 2016, art.17 e 18).
}

Na apreciação do Projeto de Autoavaliação Institucional da UEG não foi identificada nenhuma menção ao regime de colaboração no processo de avaliação da instituição. Porém, consta que os trabalhos seguirão as orientações da lei do Sinaes, das normas definidas pelo CEE/GO e da legislação própria da UEG. Nas produções acadêmicas de Nascimento (2008), 
O regime de colaboração nos processos de avaliação institucional nas universidades estaduais da Região CentroOeste: regulamentações e desafios

Queiroz (2008) e Botelho (2016) que contemplam a avaliação institucional da UEG, a categoria do regime de colaboração e seus possíveis desafios no processo da avaliação institucional da UEG não foram objeto de estudo.

\section{Considerações Finais}

A análise de como o regime de colaboração nos processos de avaliação institucional está expresso nos documentos oficiais dos estados e das UEs da região Centro-Oeste nos possibilitou levantar algumas considerações e questionamentos, sobretudo no que se refere aos possíveis desafios e contradições que o permeiam nos processos de avaliação institucional da UEG, Unemat e Uems.

Perante apreciação da legislação nacional foi possível observar algumas dificuldades quanto à efetivação dos processos de avaliação institucional nas UEs brasileiras dentro do que se entende como sendo desejável em um regime de colaboração. Este, embora previsto em lei, em especial na lei do Sinaes, encontra desafios e limites para a sua efetivação, pois as atribuições dos entes federados não estão bem definidas, revelando hiatos, imprecisões e contradições nos processos de avaliação institucional das IES estaduais.

Outro entrave identificado decorre das disputas por espaços entre os órgãos/entidades envolvidos nas discussões/definições da cooperação entre estados e União, por um lado temos os CEEs que buscam resguardar suas participações nos processos de avaliação sob a alegação da preservação das especificidades locais e preservação da autonomia dos estados, por outro temos a Conaes/Inep que buscam manter a uniformidade do Sinaes. Cabe destacar que a Conaes não possui uma representação formal dos estados em sua composição. Nesse sentido, faz-se necessário para a integração entre União e estados, o desprendimento a projetos locais/setoriais em prol de um projeto nacional que vislumbre contemplar a educação superior do Brasil como um todo e pautada em um modelo democrático e de qualidade.

$\mathrm{Na}$ segunda etapa do estudo observou-se que as UEs da região Centro-Oeste, em especial a Unemat e Uems, apresentaram desafios similares quanto às dificuldades em articular as normas/regulamentações do Sistema Estadual com o federal. Sobre os conteúdos que regulamentam os sistemas estaduais de educação superior da região Centro-Oeste, a regulação e a supervisão tendem a se sobrepor à avaliação enquanto processo que pode contribuir para a melhoria da IES. De acordo com Lima, Cunha e Silva (2014, p. 115),

A legislação vigente sobre o processo de avaliação da educação superior, principalmente no que tange a colaboração entre os entes da federação, não possibilitou a percepção de uma perspectiva democrática, tendo em vista a definição de normas em relação ao SINAES, ora 
pela federação, ora pelo Estado, normas essas que são determinação e imposição para a prática da avaliação e da regulação da IES.

A ausência ou pouca menção de como operacionalizar o regime de colaboração nos documentos apreciados não é suficiente para descartar a sua existência nos processos de avaliação institucional das universidades estaduais que compõem este estudo. Todavia constitui num possível indicativo dos desafios e limites que a União e os sistemas estaduais de educação superior e seus órgãos normativos e reguladores precisam superar para que a colaboração de fato se efetive.

A presente análise evidencia questões desafiadoras que envolvem o regime de cooperação no processo de avaliação institucional das UEs da região Centro-Oeste que precisam ser enfrentados pelos entes federados e seus órgãos normativos para que essas instituições não se tornem reféns das indefinições ainda existentes nesse cenário, pois

a aplicação do SINAES nas universidades estaduais pode estar em meio a nós que precisam ser desatados a fim de se consolidar um termo de cooperação explícito e exequível para os entes federados que possibilite a melhoria das atividades desenvolvidas pela universidade (LIMA; CUNHA; SILVA, 2014, p. 114).

Ademais, destacam-se ainda outros entraves à efetiva realização da cooperação entre os entes federados, sobretudo aspectos que dizem respeito aos trâmites da avaliação dentro das IES, tais como a dicotomia entre o que é previsto nos textos normativos e as condições concretas para a sua efetivação. Em especial destacam-se as dificuldades relativas à garantia da infraestrutura das IES para abrigarem as Comissões Próprias de Avaliação (CPA) e os Núcleos Docentes Estruturantes (NDE), bem como a disponibilidade de profissionais com dedicação (e formação) para atuarem nos processos avaliativos internos das IES. Nesse sentido, de acordo com um estudo realizado por Assis (2016),

\footnotetext{
a avaliação das instituições e de seus respectivos cursos deveria ser mais bem coordenada e divulgada pelas IES, visando a corrigir as fragilidades e lacunas existentes no processo de comunicação e de participação dos professores. [...] as avaliações institucionais têm sido conduzidas, sobretudo, para atender às exigências do MEC, nem sempre cumprindo seu papel de indutora de reflexões e mudanças no interior dos cursos e das IES. Dessa forma, empreendem-se grandes esforços na sua condução e não se colhem os bons frutos que ela, potencialmente, poderia oferecer às comunidades acadêmicas (p. 544).
}

Por fim, temos que a Unemat, a Uems e a UEG, são submetidas a um duplo e misto sistema de avaliação e, seus processos, mostram-se permeados por vários desafios que tendem a comprometer os objetivos fins dessa avaliação e dificultar a atuação das CPAs e das UEs que se veem inseridas em um contexto de ambiguidades e conflitos entre a legislação local e 
O regime de colaboração nos processos de avaliação institucional nas universidades estaduais da Região CentroOeste: regulamentações e desafios

nacional, e ainda precisam equilibrarem-se em meio a múltiplos mecanismos/instrumentos de avaliação, controle e regulação na execução dos seus processos avaliativos.

\section{Referências}

ANDRADE. Maria Edgleuma. Política de expansão da UERN: oferta e qualidade de educação superior. 2012. 250f. Tese (Doutorado) - Universidade Federal da Paraíba, João Pessoa, 2012.

ASSIS, Lúcia Maria de. Avaliação institucional e trabalho docente: repercussões, desafios e perspectivas. RBPAE, Goiânia, v. 32, n. 2, p. 527-548. maio/ago. 2016.

ASSIS, Lúcia Maria de; AMARAL, Nelson Cardoso. Avaliação da Educação: por um sistema nacional. Retratos da Escola, Brasília, v. 7, n. 12, p. 27-48, jan. / jun. 2013.

BARREYRO, Gladys Beatriz; ROTHEN, José Carlos (Orgs.). Avaliação da educação: diferentes abordagens críticas. São Paulo: Xamã, 2011.

BRASIL. Ministério da Educação. Lei n. 9.394, de 26 de dezembro de 1996. Estabelece as Diretrizes e Bases da Educação Nacional. Diário Oficial da União, Brasília, DF, 1996.

BRASIL. Ministério da Educação. Lei no 10.861, de 14 de abril de 2004. Institui o Sistema Nacional de Avaliação da Educação Superior - Sinaes e dá outras providências. Brasília: Senado Federal, 2004.

BRASIL. Ministério da Educação. Decreto n. 5.773 de 09 de maio de 2006. Dispõe sobre o exercício das funções de regulação, supervisão e avaliação de instituições de educação superior e cursos superiores de graduação e sequenciais no sistema federal de ensino, DF, 2006.

BRASIL. Ministério da Educação. Instituto Nacional de Estudos e Pesquisas Educacionais Anísio Teixeira. Censo da Educação Superior de 2015. Brasília: Inep, 2015 a.

BRASIL. Ministério da Educação. Instituto Nacional de Estudos e Pesquisas Educacionais Anísio Teixeira. Comissão Nacional de Avaliação da Educação Superior. Diretoria de Avaliação da Educação Superior (DAES). Nota Técnica Inep/Daes/Conaes n. ${ }^{\circ} 065$. Brasília, 2015b.

BOTELHO, Arlete de Freitas. Intencionalidades e efeitos da autoavaliação institucional na gestão de uma universidade multicampi. 2016. 381p. Tese (Doutorado). Universidade de Brasília, Brasília, DF, 2016.

CARVALHO, Renata Ramos da Silva. Universidade Estadual de Goiás: histórico, realidade e desafios. 2013. 202f. Dissertação (Mestrado) - Universidade Federal de Goiás, Goiânia, GO, 2013.

FIALHO, Nadia Hage. Universidades estaduais no Brasil: pauta para a construção de um sistema nacional articulado de educação. Revista da FAEEBA - Educação e

Contemporaneidade, Salvador, v. 21, n. 38, p. 81-93, jul./dez. 2012.

GOIÁS. Conselho Estadual de Educação - CEE/GO. Resolução n. 03 de 29 de abril de 2016. Estabelece normas para o Sistema Estadual de Educação Superior do Estado de Goiás. CEE/GO, Goiânia-GO, 2016. 
LIMA, Elizeth Gonzaga dos Santos; CUNHA, F.L S. J; SILVA, J. S. O. SINAES e a legislação aplicável no Sistema Estadual: o regime de colaboração. Rev. Fac. Educ., Mato Grosso, v. 21, n. 1, p. 99-118, jan/jun. 2014.

MATO GROSSO. Conselho Estadual de Educação. Termo de Cooperação Técnica com MEC/SINAES, de 05 de abril de 2005. Dispõe sobre o regime de colaboração/cooperação previsto na legislação para ampliar atuação do CEE/MT nos processos de avaliação externa preconizada pelo SINAES e dá outras providências. Cuiabá-MT: CEE/MT, 2005.

MATO GROSSO. Conselho Estadual de Educação. Resolução Normativa n. ${ }^{\circ}$ 311/2008, de 15 de julho de 2008. Dispõe sobre normas para a organização, o funcionamento e o processo de regulação e de supervisão das Instituições de Ensino Superior e de seus cursos, pertencentes ao Sistema Estadual de Ensino de Mato Grosso, e dá outras providências. Cuiabá-MT: CEE/MT, 2008.

MATO GROSSO DO SUL. Conselho Estadual de Educação. Deliberação CEE/MS no 9042, de 27 de fevereiro de 2009. Estabelece normas para a regulação, a supervisão e a avaliação de instituições de educação superior e de cursos de graduação e sequenciais no sistema estadual de ensino de Mato Grosso do Sul. Campo Grande, MS: CEE/MS, 2009.

MATO GROSSO DO SUL. Universidade Estadual de Mato Grosso do Sul. Comissão Própria de Avaliação Institucional - Projeto de Avaliação Institucional ciclo 2012 a 2015. Mato Grosso do Sul. Dourados-MS: UEMS, 2013.

MATO GROSSO (Universidade Estadual de Mato Grosso - UNEMAT). Projeto de Avaliação Institucional ciclo 2015 a 2018. Mato Grosso. Cáceres-MT: UNEMAT, 2015.

NASCIMENTO, Marlúcio Tavares do. A institucionalização da auto-avaliação na Universidade Estadual de Goiás (UEG): avanços, limites e desafios. 2008. $191 \mathrm{f}$. Dissertação (Mestrado) - Universidade Federal de Goiás, Goiânia, 2008,

OLIVEIRA, Edmar Bonfim de. A avaliação da educação superior e o regime de colaboração no contexto das Instituições Públicas Estaduais: a experiência da Universidade Estadual do Paraná. 2015. 248p. Tese (Doutorado) - Universidade Estadual de Maringá, Maringá, 2015.

QUEIROZ, Kelli Consuêlo Almeida de Lima. Eu avalio, tu avalias, nós nos autoavaliamos? A experiência da Unidade Universitária de Ciências Sócio-Econômicas e Humanas - UNUCSEH/UEG com a auto avaliação proposta pelo SINAES. 2008. 177f. Dissertação (Mestrado) - Universidade de Brasília, Brasília, 2008.

SGUISSARDI, Valdemar (Org.). Avaliação universitária em questão: reformas do Estado e da educação superior. Campinas: Autores Associados, 1997.

SOUZA, Marianne Pereira de. Avaliação da educação superior na interseção de políticas sistêmicas e institucional. 2012. 109f. Dissertação (Mestrado) - Universidade Federal da Grande Dourados, Dourados, 2012.

TRINDADE, H. Desafios, institucionalização e imagem pública da CONAES. Brasília: UNESCO; MEC, 2007. 
O regime de colaboração nos processos de avaliação institucional nas universidades estaduais da Região CentroOeste: regulamentações e desafios

Renata Ramos da Silva Carvalho

${ }^{1}$ Universidade Estadual de Goiás |

Goiânia | GO | Brasil. Contato: renataramosprof@yahoo.com.br

ORCID (iD) 0000-0002-7461-6698

Lúcia Maria de Assis

${ }^{2}$ Universidade Federal de Goiás | Faculdade de Educação Goiânia | GO | Brasil. Contato: luciamariadeassis@gmail.com

ORCID (iD) 0000-0002-6380-2129

Artigo recebido em 23 de novembro de 2016 e aprovado em 25 de setembro de 2017. 